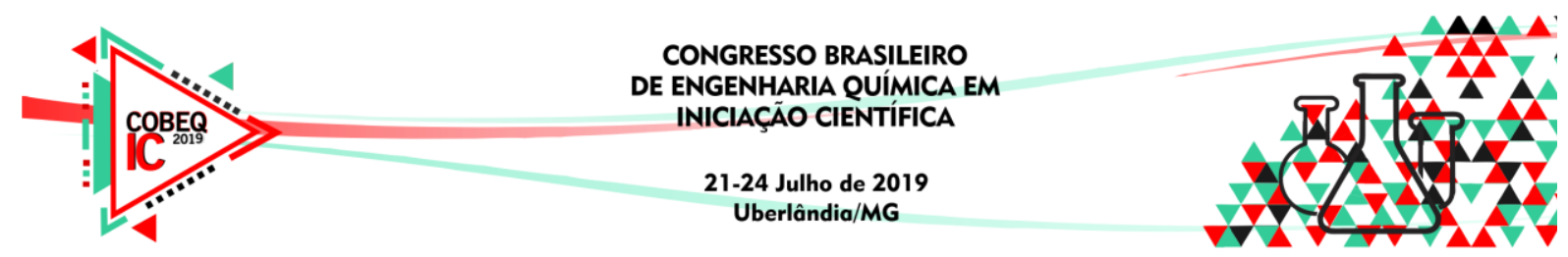

\title{
ESTUDO CINÉTICO DO PECÍOLO DE BURITI COMO BIOSSORVENTE DO CORANTE AZUL DE METILENO
}

\author{
A. R. de OLIVEIRA ${ }^{1}$, G. Thompson, R. N. da CUNHA ${ }^{1}$ \\ ${ }^{1}$ Centro Universitário de Patos de Minas, Departamento de Engenharia Química \\ E-mail para contato: anamariardo@gmail.com
}

\begin{abstract}
RESUMO - As indústrias têxteis estão entre as empresas que mais utilizam corantes durante o processo produtivo, entretanto, devido à baixa taxa de fixação ao longo de seu processamento, grande parcela é descartada nos efluentes industriais. Nesse sentido, o processo de adsorção empregando descartes agrícolas destaca-se como um método alternativo para o tratamento desses efluentes, devido ao custo reduzido e significativa eficiência na remoção dos poluentes. Dentro desse contexto, o presente estudo objetivou avaliar a capacidade do pecíolo de Buriti (Mauritia flexuosa L.f.) sobre a adsorção do corante azul de metileno. Os ensaios experimentais foram conduzidos em sistema batelada, determinando-se o ponto de carga zero, a cinética de adsorção e o ajuste dos modelos teóricos preditivos. $\mathrm{O}$ ponto de carga zero $\left(\mathrm{pH}_{\mathrm{PZC}}\right)$ obtido para o pecíolo de Buriti foi de 6,5. O adsorvente se mostrou satisfatório, pois apresentou porcentagens de remoção de corante acima de $90 \%$. Os estudos cinéticos revelaram que a equação de Pseudo-segunda ordem forneceu os melhores ajustes aos dados experimentais.
\end{abstract}

\section{INTRODUÇÃO}

A indústria têxtil é uma das principais atividades industriais no mundo, representando no Brasil 5\% do PIB nacional. O setor têxtil necessita de grandes quantidades de água em seus processos, ou seja, $15 \%$ de toda água industrial no país. A água elimina resíduos indesejáveis nas fibras e também transporta produtos químicos até o tecido, como, por exemplo, os corantes. Sendo assim, os efluentes das indústrias têxteis são significativamente contaminados e coloridos (COGO, 2011).

Alguns processos são utilizados para amenizar a concentração de corantes nos efluentes, sendo a adsorção vista como a mais eficaz e economicamente viável. Todavia, adsorventes com alto potencial de remoção possuem elevado custo o que dificulta sua aplicação na escala industrial, a título de exemplo o carvão ativado, que possui grande poder de adsorção, porém seu uso torna-se excessivamente dispendioso (SILVA et al., 2012).

No segmento de biossorventes cita-se o pecíolo (caule foliar) do Buriti como adsorvente alternativo para remoção de corantes e outros contaminantes. O Buriti (Mauritia flexuosa L.F.) é uma palmeira encontrada na região amazônica, próxima a áreas alagadas. É uma importante fonte de renda na região, sendo matéria-prima para fabricação de diversos produtos, como artesanatos, brinquedos, doces, picolés e produção de álcool combustível. 


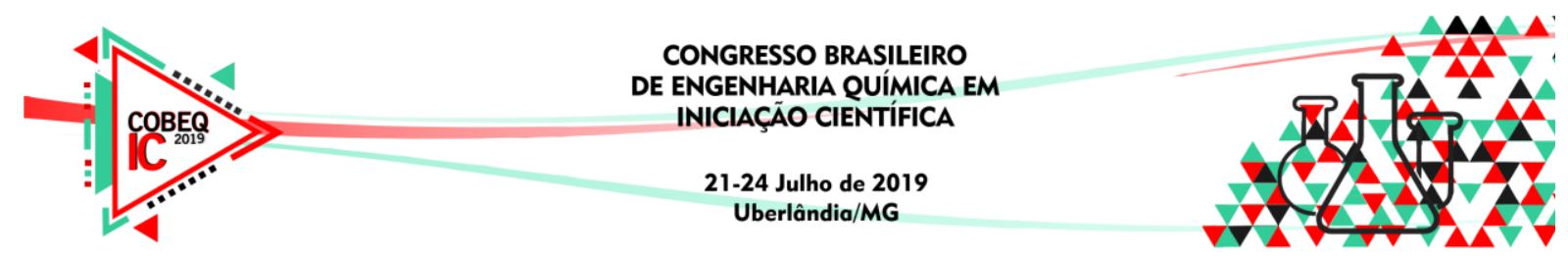

Rico em vitamina A, é bastante utilizado na culinária local. O óleo extraído dos frutos vem sendo utilizado na fabricação de protetor solar e desodorante corporal (CYMERYS, 2010).

Pesquisas envolvendo o pecíolo de Buriti como adsorvente de corantes, dentre eles o azul remazol, vêm sendo realizadas no âmbito científico. Silva et al. (2012) verificaram que o processo é influenciado por diversos fatores, tais como carga superficial do adsorvente, $\mathrm{pH}$, tempo de equilíbrio e concentração inicial do corante. Nesse sentido, o presente estudo visa verificar a eficácia do pecíolo de Buriti sobre a adsorção do azul de metileno, corante presente em efluentes têxteis industriais. Faz ainda parte do escopo desta pesquisa o estudo cinético da adsorção e a determinação do ponto de carga zero.

\section{METODOLOGIA}

\subsection{Material adsorvente}

A coleta do biomaterial foi realizada em uma fazenda no município de Brasilândia de Minas, cidade localizada no Noroeste de Minas Gerais. O material coletado foi envolto em plástico escuro, evitando-se desse modo sua exposição à luz e armazenado em local seco. Posteriormente as amostras foram conduzidas ao Laboratório de Engenharia QuímicaUNIPAM. Como objeto de estudo utilizou-se o caule foliar do buritizeiro, conhecido como pecíolo, o qual foi picado e triturado em liquidificador industrial marca METVISA. O material in natura foi submetido a um conjunto de peneiras vibratórias para classificação granulométrica das partículas.

\subsection{Preparo das soluções de corante azul de metileno}

As soluções de azul de metileno foram obtidas pela diluição do reagente PA. em pó, sendo preparadas soluções nas concentrações de 0,1 a $30 \mathrm{mg} . \mathrm{L}^{-1}$, utilizando-se para tanto, água destilada e deionizada. Os ajustes no valor de $\mathrm{pH}$ foram realizados com adição de ácido clorídrico $\left(0,1 \mathrm{~mol} . \mathrm{L}^{-1}\right)$ ou hidróxido de sódio $\left(0,1 \mathrm{~mol} . \mathrm{L}^{-1}\right)$. Para monitorar o processo de adsorção do corante adotou-se o comprimento de onda de $661 \mathrm{~nm}$ (espectrofotômetro UV/Vis marca Genesys 10uv). O coeficiente de determinação $\left(\mathrm{R}^{2}\right)$ da curva de calibração foi de 0,9984 , indicativo de boa linearidade dos pontos e elevado ajuste aos dados experimentais.

\subsection{Ponto de carga zero}

Para o pecíolo de Buriti avaliou-se o ponto de carga zero, definido como o $\mathrm{pH}$ em que a superfície do sólido possui carga neutra. O mesmo foi obtido adicionando-se $0,1 \mathrm{~g}$ do biossorvente em $25 \mathrm{~mL}$ de solução de $\mathrm{NaCl}\left(0,1 \mathrm{~mol} . \mathrm{L}^{-1}\right) \mathrm{com} \mathrm{pH}$ variando de 1 a 12 . Tais pHs foram ajustados com soluções de $\mathrm{HC} \ell\left(0,1 \mathrm{~mol} . \mathrm{L}^{-1}\right)$ e $\mathrm{NaOH}\left(0,1 \mathrm{~mol} . \mathrm{L}^{-1}\right)$ utilizando-se o pHmetro marca MS Tecnopon. As misturas ficaram em contato por $24 \mathrm{~h}$ sendo essas, posteriormente, filtradas. Para os filtrados obtidos foram avaliados seus $\mathrm{pHs}$. Os resultados foram expressos por meio do gráfico de $\mathrm{pH}$ final versus $\mathrm{pH}$ inicial, sendo que o $\mathrm{pH}_{\mathrm{PCZ}}$ corresponderá à faixa em que o $\mathrm{pH}$ final se mantiver constante (independentemente do $\mathrm{pH}$ inicial), ou seja, a superfície comporta-se como um tampão. 


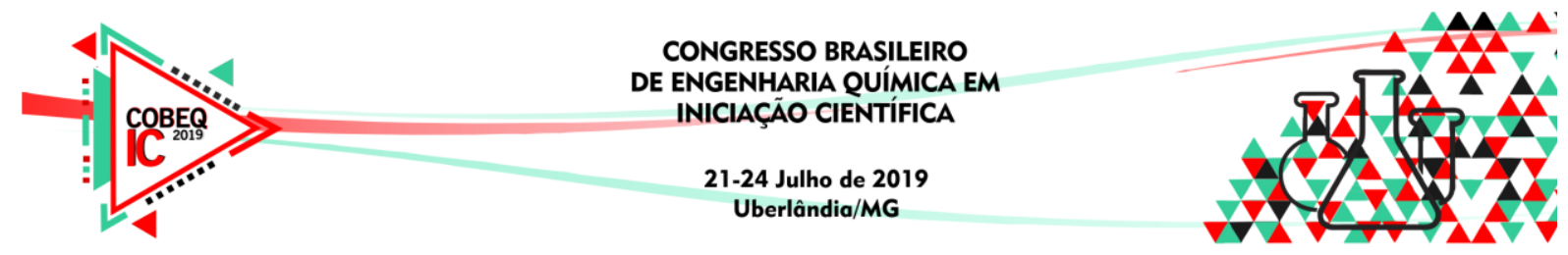

\subsection{A cinética de adsorção}

Para a determinação da cinética de adsorção, adicionaram-se $0,5 \mathrm{~g}$ de adsorvente a 100 $\mathrm{mL}$ de solução de adsorbato, mantidas constantes as condições operacionais: concentração de corante $\left(22,4 \mathrm{mg} . \mathrm{L}^{-1}\right), p \mathrm{H}(7)$ e granulometria (-9+16 mesh). Os ensaios foram repetidos em intervalos distintos de tempo até obtenção do equilíbrio. Após a adsorção as amostras foram submetidas à filtração, sendo determinadas as concentrações das soluções remanescentes por meio de técnicas espectrofotométricas. Para o estudo cinético, os resultados experimentais foram ajustados aos modelos teóricos descritos na Tabela 1.

Tabela 1- Modelos matemáticos de cinética de adsorção

\begin{tabular}{|l|c|}
\hline \multicolumn{1}{|c|}{ Designação do modelo } & Modelo \\
\hline Pseudo-primeira ordem & $q_{t}=q_{e}\left(1-e^{-k_{1} t}\right)$ \\
\hline Pseudo-segunda ordem & $q_{t}=q_{e}^{2} k_{2} t /\left(1+q_{e} k_{2} t\right)$ \\
\hline Weber e Morris & $q_{t}=k_{d} t^{1 / 2}+c$ \\
\hline Elovich & $q_{t}=\frac{1}{\beta} \ln (\alpha \beta)+\frac{1}{\beta} \ln t$ \\
\hline
\end{tabular}

Fonte: Nascimento (2014)

\section{RESULTADOS E DISCUSSÃO}

\subsection{Ponto de carga zero}

Dentre os parâmetros que afetam a capacidade de adsorção dos cátions metálicos no biossorvente destaca-se o $\mathrm{pH}$ do meio, devido à competição existente por sítios ativos e espécies protônicas e os íons metálicos (VAGHETTI, 2009). O estudo $\mathrm{pH}_{\mathrm{PCZ}}$ do adsorvente indica o valor de $\mathrm{pH}$ no qual um sólido apresenta carga eletricamente nula em sua superfície, ou seja, o número de cargas positivas é igual ao número de cargas negativas. Quando o $\mathrm{pH}$ da solução é menor do que o $\mathrm{pH}_{\mathrm{PCZ}}$ do material sólido a superfície deste ficará carregada positivamente, enquanto que se o $\mathrm{pH}$ da solução for maior do que o $\mathrm{pH}_{\mathrm{PCZ}}$ do material sólido a superfície deste ficará carregada negativamente (DEOLIN, 2013). Silva et al. (2012) acrescentam que este parâmetro se destaca na avaliação da adsorção pois permite predizer os efeitos do $\mathrm{pH}$ sobre a carga na superfície do adsorvente. A Figura 1 explicita a relação entre o $\mathrm{pH}$ inicial e o $\mathrm{pH}$ final obtida para o pecíolo de Buriti.

Observa-se pela Figura 1 que o ponto de carga zero, que se dá pela média aritmética dos pontos que possuem $\mathrm{pH}$ final constante, sendo esse de 6,5. Ressalta-se que quando se empregam soluções com $\mathrm{pH}$ acima do ponto de carga zero, a superfície se carrega negativamente, adsorvendo cátions, sendo mais eficaz no emprego de corantes catiônicos (DEOLIN et al., 2013). Destaca-se que o corante orgânico azul de metileno, tem como nomenclatura química cloridrato de metiltiamina, e composição química $\mathrm{C}_{16} \mathrm{H}_{18} \mathrm{SN}_{3} \mathrm{C} \ell .3 \mathrm{H}_{2} \mathrm{O}$. Trata-se de um corante catiônico, ou seja, em solução aquosa, dissocia-se em cátions de azul de metileno (MERCK \& CO, 1952). Portanto, a adsorção ocorre de modo mais efetivo para as condições de $\mathrm{pH}$ acima do ponto de carga zero. 


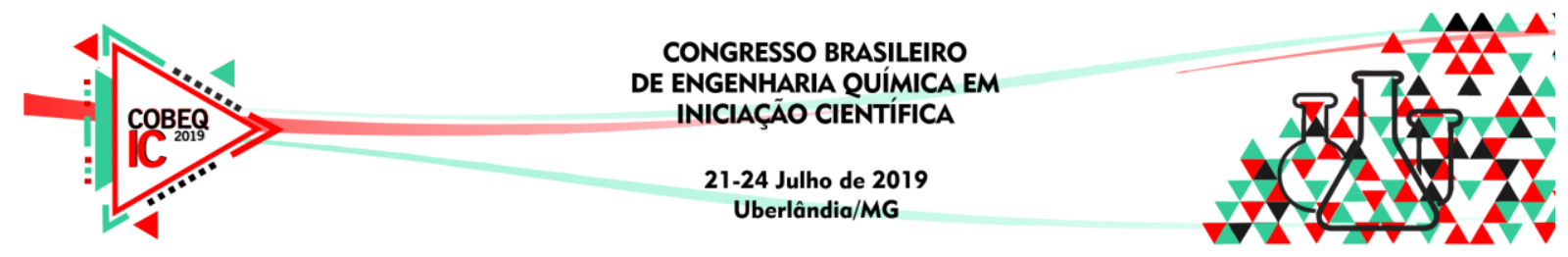

Figura 1- Determinação do ponto de carga zero para o pecíolo de Buriti

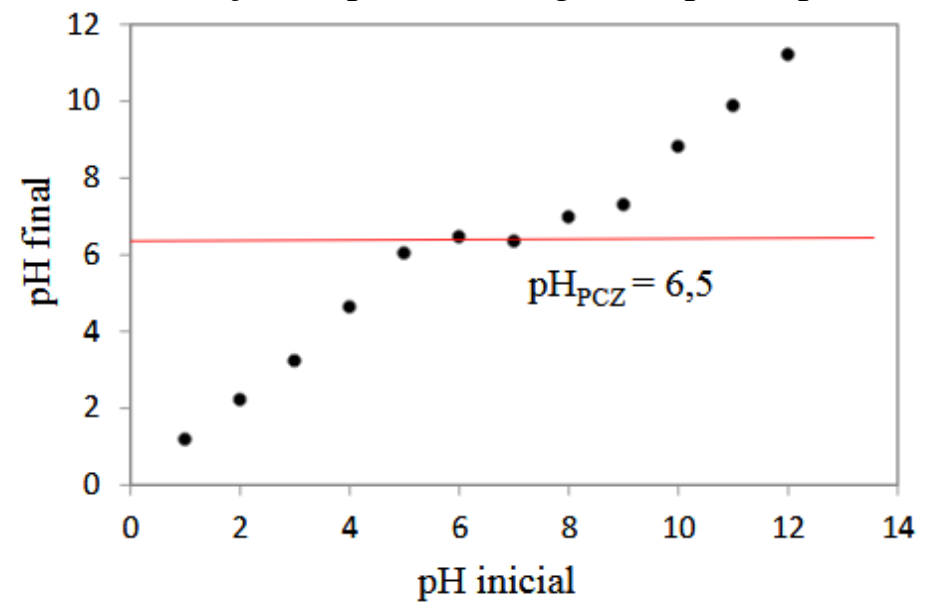

\subsection{Cinética de adsorção}

A cinética representa a velocidade de adsorção das moléculas do adsorbato na superfície do adsorvente. Os resultados da cinética são apresentados na Figura 2, em que se evidencia que o estado estacionário, ou seja, tempo de equilíbrio é atingido após 87 minutos. Observa-se que já no primeiro minuto ocorre uma remoção de $90 \%$ e que o percentual de remoção de azul de metileno atinge $98,6 \%$, demonstrando que o pecíolo de Buriti se mostra um adsorvente com alta eficiência em um curto período de tempo.

Figura 2 - Efeito do tempo na adsorção de azul de metileno em pecíolo de Buriti

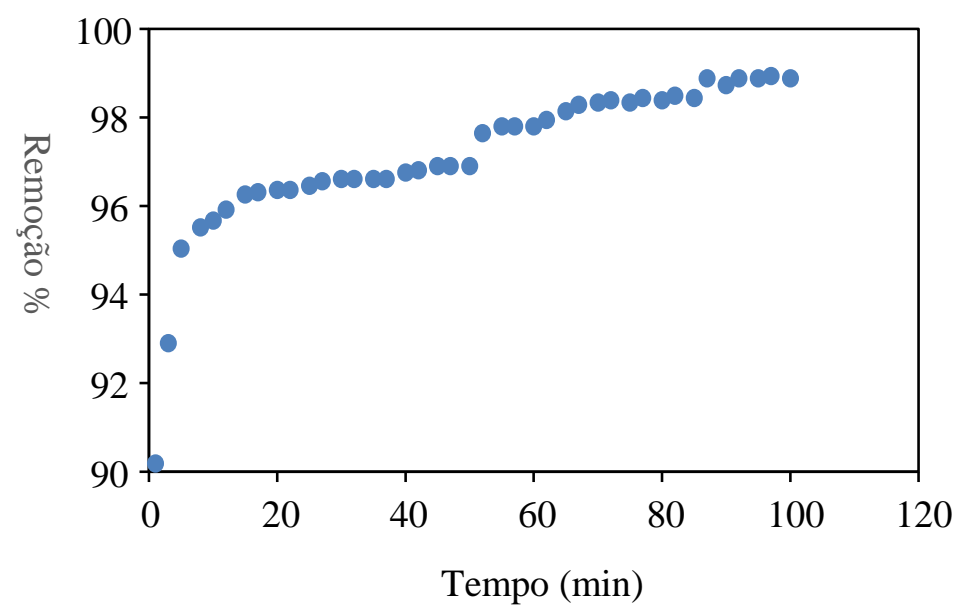

Lima (2017) ao empregar o pecíolo de Buriti em seus estudos, observou um percentual de remoção de $60 \%$ no primeiro minuto, e seu tempo de equilíbrio foi atingido após 30 minutos de ensaio, além de obter um valor máximo de $95 \%$. Essa discrepância se deve à diferença dos métodos aplicados, uma vez que o autor utilizou ensaio contínuo em coluna de leito fixo.

Segundo Silva (2005) o mecanismo de adsorção de corantes pode envolver quatro estágios: (a) difusão de moléculas da solução para a camada periférica do adsorvente; (b) 


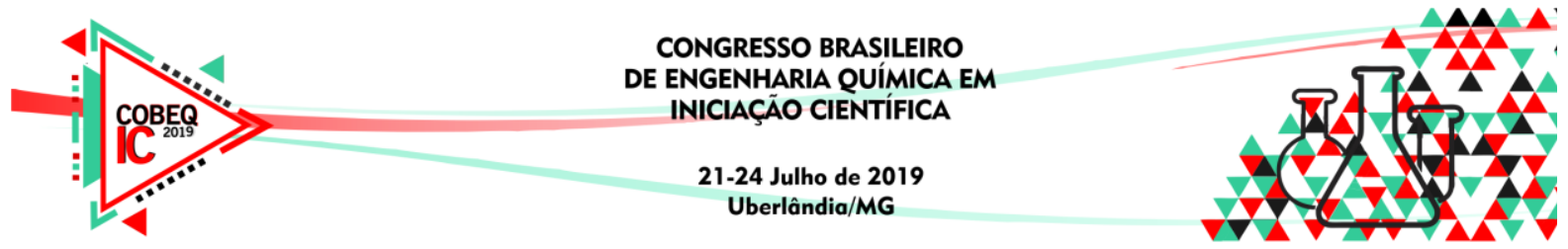

difusão das moléculas na interface e adsorção pelos sítios da superfície externa; (c) difusão de moléculas para dentro dos poros do adsorvente (difusão intrapartícula); (d) interação das moléculas com os sítios disponíveis na superfície interna, ligando aos espaços porosos e capilares do adsorvente. Destaca-se que a velocidade de adsorção e a quantidade de corante adsorvida dependem de um ou mais estágios indicados e estão relacionadas às interações eletrostáticas entre adsorvente/adsorbato quando o adsorvente possui uma carga superficial. Visando avaliar a etapa determinante na velocidade de adsorção do azul de metileno pelo pecíolo de Buriti, modelos cinéticos teóricos foram empregados sendo suas constantes e coeficientes de determinação explicitados pela Tabela 2 .

Os resultados apontam que processo de adsorção se ajustou melhor ao mecanismo de Pseudo-segunda ordem, fato esse evidenciado pelo coeficiente de determinação $\left(\mathrm{R}^{2}\right)$ de 0,9939 e pelo erro menor que 0,05. A predição pelo modelo de Pseudo-segunda ordem revela que o processo envolve um mecanismo de adsorção ativado ou quimissorção, e que é um tipo de adsorção de caráter intermediário entre a adsorção química e física (FUNGARO; BORRELY; CARVALHO, 2010). O resultado também foi confirmado pelo melhor ajuste dos valores experimentais de qt em relação aos preditos pelo modelo (Figura 3).

Tabela 2 - Ajuste de modelos teóricos para predição de cinética de adsorção

\begin{tabular}{|l|l|c|c|}
\hline \multicolumn{1}{|c|}{ Modelos } & \multicolumn{1}{|c|}{ Parâmetros dos modelos } & $\mathrm{R}^{2}$ & $\mathrm{SE}$ \\
\hline \hline Pseudo-primeira ordem & $\begin{array}{l}\mathrm{K}_{1}=2,825 \mathrm{~min}^{-1} \\
\mathrm{q}_{\mathrm{e} C \mathrm{LL}}=4,293 \mathrm{mg} \cdot \mathrm{g}^{-1} \\
\mathrm{q}_{\mathrm{e} \text { EXP }}=4,430 \mathrm{mg} \cdot \mathrm{g}^{-1}\end{array}$ & 0,9674 & 0,024 \\
\hline Pseudo-segunda ordem & $\begin{array}{l}\mathrm{K}_{2}=3,018 \mathrm{~g} \cdot \mathrm{mg}-1 \cdot \mathrm{min}^{-1} \\
\mathrm{q}_{\mathrm{e} \text { ALL }}=4,327 \mathrm{mg} \cdot \mathrm{g}^{-1} \\
\mathrm{q}_{\mathrm{e} \text { EXP }}=4,430 \mathrm{mg} \cdot \mathrm{g}^{-1}\end{array}$ & 0,9939 & 0,004 \\
\hline Elovich & $\begin{array}{l}\alpha=2,56 \mathrm{E}+09 \mathrm{mg} \cdot \mathrm{g}^{-1} \cdot \mathrm{min}^{-1} \\
\beta=6,062 \mathrm{~g} \cdot \mathrm{mg}^{-1}\end{array}$ & 0,8708 & 0,093 \\
\hline Weber e Morris & $\begin{array}{l}\mathrm{K}_{\mathrm{d}}=0,051 \mathrm{mg} \mathrm{g} \mathrm{g}^{-1} \cdot \mathrm{min}^{-0.5} \\
\mathrm{C}=4,087 \mathrm{mg} \cdot \mathrm{g}^{-1}\end{array}$ & 0,9701 & 0,022 \\
\hline
\end{tabular}

Figura 3- Resultados experimentais e ajuste dos modelos cinéticos de adsorção

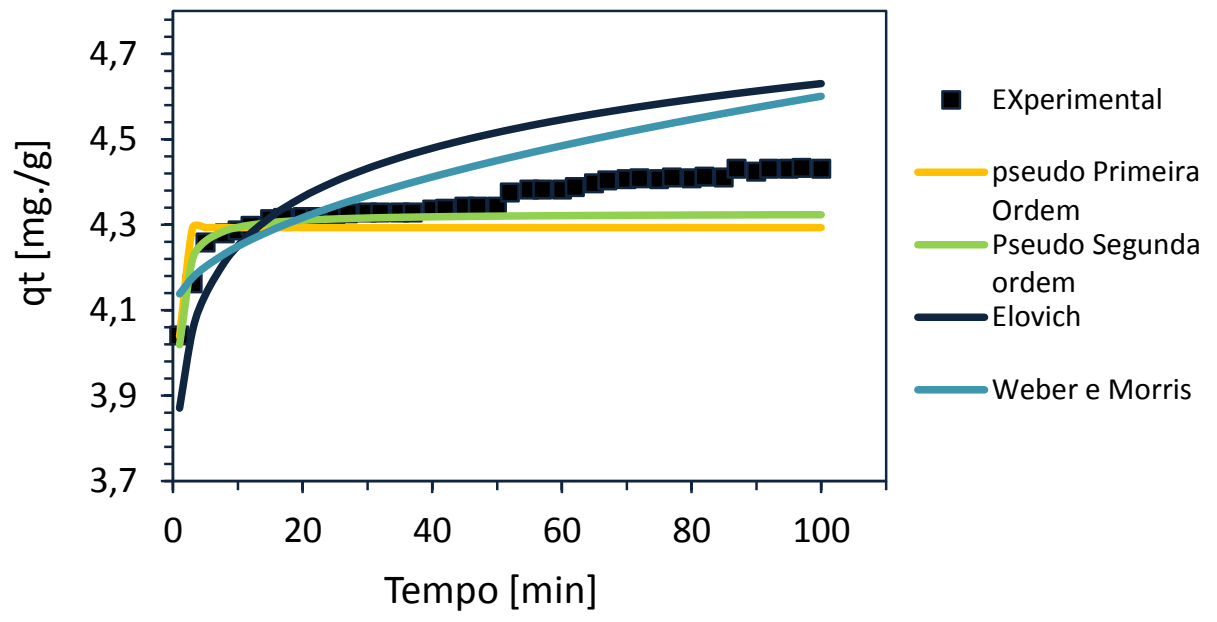




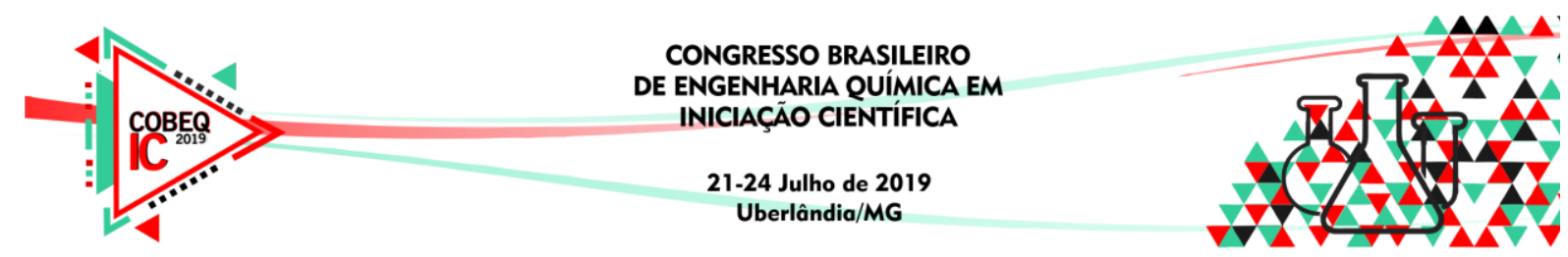

\section{CONCLUSÃO}

A partir dos estudos de adsorção de azul de metileno utilizando pecíolo de Buriti ressalta-se que:

- O ponto de carga zero obtido para o biossorvente foi de 6,5 , ou seja, a adsorção de azul de metileno é favorecida em soluções com $\mathrm{pH}$ acima do ponto de carga zero.

- O pecíolo de Buriti se mostrou ser eficaz frente à adsorção do corante azul de metileno, obtendo-se remoções acima de $90 \%$.

- Os resultados apontam que a utilização do pecíolo do Buriti apresenta ser uma alternativa vantajosa, econômica e ambientalmente viável.

\section{REFERENCIAS}

COGO, Marina da Cunha. Estudo de caracterização e disposição dos resíduos de uma indústria têxtil do estado do Rio Grande do Sul. Porto Alegre, Escola de engenharia da UFRGS, 2011

CYMERYS, Margareth. Buriti, frutíferas e plantas úteis na vida amazônica. 2. ed. Mauritia flexuosa L.f. Centro Internacional para Pesquisa Florestal (Cifor), 2010

DEOLIN, Mara Helen da Silva et al. Obtenção do ponto de carga zero de materiais adsorventes. In: ENCONTRO INTERNACIONAL DE PRODUÇÃO CIENTÍFICA CESUMAR, $8^{\circ} \mathrm{ed}$. 2013, Maringá. Anais. Maringá: Cesumar, p. 1 -4. 2013

FUNGARO, Denise Alves; BORRELY, Sueli I.; CARVALHO, Terezinha E. M. Remoção do corante reativo Laranja 16 de solução aquosa usando zeólita de cinzas de carvão modificada por surfactante. In: Congresso internacional de tecnologias para o meio ambiente, $2^{\circ} \mathrm{Ed}$., 2010, Bento Gonçalves - RS. Anais. São Paulo - SP: IPE. p. 1 - 8.2010

LIMA, Sara Nepomuceno Patriota. Caracterização das fibras de buriti e sua aplicabilidade como adsorvente de metais e corantes. 2017, 97 f. Dissertação (Mestrado) - Curso de Biotecnologia, Universidade Federal do Tocantins, Gurupi - TO, 2017

MERCK E CO. The Merck Index of Chemical and Drugs. Rahway, Merck \& CO., Inco. 1952.

NASCIMENTO, Ronaldo Ferreira do; LIMA, Ari Clecius Alves de; VIDAL, Carla Bastos; MELO, Diego de Quadros; RAULINO, Giselle Santiago Cabral. ADSORÇÃO: Aspectos teóricos e aplicações ambientais. Fortaleza: Imprensa Universitária, p. ,2014

SILVA, A. T. Influência da temperatura na adsorção do corante azul de metileno utilizando serragem de Pinus Elliottii como um adsorvente alternativo: um modelo para o tratamento de efluentes têxteis. Universidade Federal de Santa Catarina, Florianópolis, 2005.

SILVA, Domingos S. A. et al. Adsorção do corante têxtil azul remazol por pecíolo de buriti (Mauritia flexuosa L.f.). Cadernos de Pesquisa, São Luis - MA, v. 19, ed. especial, p.138146, jul. 2012.

VAGHETTI, J. C. P. Utilização de Biossorventes para Remediação de Efluentes Contaminados por Íons Metálicos. 2009. 99f. Tese (Doutorado em Química). Programa de Pós-Graduação em Química. Universidade Federal do Rio Grande do Sul, Porto Alegre, 2009. 